\begin{tabular}{l|c|c|}
\hline $\mathrm{r} 89^{6}$ & $\Delta \alpha$ & $\Delta \delta$ \\
\hline \multicolumn{3}{|c|}{ (80) Sa ppho. } \\
[Berl. Jahrb. 1898]. \\
Oct. 30 & -0.39 & +2.2 \\
Nov. 5 & -0.18 & +1.5
\end{tabular}

\begin{tabular}{|l|c|c|}
\hline 1896 & $\Delta \alpha$ & $\Delta \delta$ \\
\hline \multicolumn{3}{|c|}{$(82)$ Alkmene. } \\
[Berl. Jahrb. 1898]. \\
Nov. I3 & -1.50 & -5.6 \\
I 4 & -1.53 & -6.3
\end{tabular}

\begin{tabular}{|c|c|c|}
\hline 1896 & $\Delta \alpha$ & $\Delta \delta$ \\
\hline \multicolumn{3}{|c|}{ (354) (1893 A). [A.N. 141.237]. } \\
\hline Oct. 30 & +9.77 & $+24: 0$ \\
\hline \multicolumn{3}{|c|}{$\left(3^{87}\right)(\mathrm{r} 894 \mathrm{AZ})$. [Astr. J. XVII.4] } \\
\hline Nov. 29 & +1.42 & -0.2 \\
\hline
\end{tabular}

Bemerkungen.

Die Beobachtungen sind wieder am Refractor von Sehr schwierige Beobachtung. -- Nov. 29 . Comet heller I $74 \mathrm{~mm}$ Objectivöffnung mit dem Glaskreismikrometer an-: gestellt.

Comet 1896 VII (Perrine). Dec. 29. Comet bei nebeliger Luft kaum zu sehen. Genaue Positionsbestimmung unmöglich.

Comet $1897 \ldots$ (Perrine I896 Nov. 2). Nov. 5 .

Jena, Grossherzogl. Sternwarte, 1897 Jan. 2 I. und leichter zu beobachten als Nov. 5 und 7. - Dec. 3 . Beobachtung wahrscheinlich nicht schlecht. - Dec. 4. Comet steht zu nahe bei einem Sternchen Io. Grösse, um gut beobachtet werden zu können; Beobachtung daher unterlassen.

(163) Erigone. Vergebens gesucht.

Otto Knopf.

\title{
Discovery of three close Southern Binaries
}

$\psi$ Velorum, p Velorum, and $\lambda$ Lupi, made with the 24 inch Refractor of the Lowell Observatory. By $T . \mathcal{F} . \mathcal{F}$. See.

In the course of our examination of southern stars a number of bright objects heretofore supposed to be single have proved to be close doubles, and several wide pairs have been resolved into triple systems of high interest. Three of the close pairs recently discovered are particularly important, as likely to have rapid orbital motion, and they will therefore be of interest to other observers.

1). $\psi$ Velorum, discovered 1897 , Jan. 31 .

$$
a=9^{\mathrm{h}}{ }^{2} 6^{\mathrm{m}} 46.6, \delta=-40^{\circ} \mathrm{I}^{\prime} 5^{\mathrm{s}} .5 \text { (1900.0). }
$$

\begin{tabular}{ccccc}
$t$ & $\theta_{o}$ & $\varrho_{o}$ & Mags. & Colors \\
1897.082 & $260^{\circ} \pm$ & $0.60 \pm$ & $5,5.1$ & both yellow \\
1897.085 & 257.8 & 0.54 & $4.9,5$ & $\geqslant$ \\
1897.086 & 258.7 & 0.49 & $5,5.3$ & $\geqslant$ \\
\hline 1897.084 & 258.8 & 0.54 & $5,5.1$ & both yellow.
\end{tabular}

By Mr. Cogshall.

$\begin{array}{lllll}1897.085 & 256.9 & 0.81 & 5\end{array}, 5 \quad$ both yellow
2) p Velorum, discovered 1897 , Jan. $\mathbf{~} 0$.

\begin{tabular}{|c|c|c|c|c|c|}
\hline \multirow{4}{*}{$\begin{array}{c}t \\
\mathrm{r} 897.025 \\
\mathrm{I} 897.085 \\
\mathrm{I} 897.086\end{array}$} & \multirow{2}{*}{$\begin{array}{c}\theta_{o} \\
275^{\circ} \circ\end{array}$} & \multirow{2}{*}{$\begin{array}{c}\rho_{o} \\
0.4_{42}\end{array}$} & Mags. & \multicolumn{2}{|c|}{ Colors } \\
\hline & & & 4,5 & both & yellow \\
\hline & 265.5 & 0.48 & $4.8,5.2$ & $»$ & $\gg$ \\
\hline & 266.3 & 0.52 & $5,5.3$ & $»$ & $»$ \\
\hline 897.065 & 268.9 & 0.47 & $4.6,5.2$ & both & yellow \\
\hline
\end{tabular}

By Mr. Cogshall.

$\begin{array}{lllll}1897.085 & 261.4 & 0.66 & 5 & , 5.2\end{array}$ both yellow

This system has a striking resemblance to $\beta$ Delphini.

3) $\lambda$ Lupi, discovered 1897, Febr. $\mathbf{~}$.

$\alpha={ }_{1} 5^{\mathrm{h}} 2^{\mathrm{m}} 7^{\mathrm{s}} \cdot 2, \delta=-44^{\circ} 53^{\prime} 3^{\mathrm{I}} .5$.

\begin{tabular}{lllll} 
I 897.085 & I 77.3 & 0.30 & $4.9,5.4$ & both yellow \\
1897.086 & I $80.0 \pm$ & $0.30 \pm$ & $4.9,5.4$ & " \\
\hline I 97.08 .5 & I 78.6 & 0.30 & $4.9,5.4$ & both yellow
\end{tabular}

Lowell Observatory, City of Mexico, Mexico, I897 Febr. 9.

T. F. F. See.

\section{On the Iron Lines present in the Hottest Stars.}

\section{Preliminary Note. By F. Norman Lockyer, C. B., F. R. S.}

[Communication made to the Royal Society].

In continuation of investigations communicated to the Royal Society in $1879^{*}$ and $1881+$, on the effect of hightension electricity on the line spectra of metals, I have recently used a more powerful current and larger jar surface than that I formerly employed.

The former work consisted in noting ( $\mathbf{I}$ ) the lines brightened in passing a spark in a flame charged with metallic vapours, and (2) the lines brightened on passing from the arc to the spark. It was found, in the case of iron, that two lines in the visible spectrum at 4924.1 and $5 \circ 18.6$, on Rowland's scale, were greatly enhanced in brightness, and were very important in solar phenornena.

$\dagger$ Roy. Soc. Proc., 1881, vol. 32, p. 204. 